\title{
Developing Teachers' Approaches to Language Learning Technologies in EFL Classroom
}

\author{
Lili Zhang \\ School of Foreign Languages and Cultures, Beijing Wuzi University, Beijing, China \\ mywritingclass@163.com
}

\begin{abstract}
The mid- to late 1990s was an exciting time for those concerned with introducing new technology into their teaching of English as foreign language (EFL). Commonly referred to as Computer-Assisted Language Learning (CALL), or sometimes with the broader term Technology-Enhanced Language Learning (TELL), the field took huge leaps forward during these years. However, in area of CALL, there existed miscommunication among researchers and practitioners without a clear understanding of the source of different assumptions. This paper focuses on the approaches to using modern technologies in the classroom that are especially useful for EFL teachers to consider. The model is presented, its significance is analyzed, and therefore activity ideas are provided that aim to help teachers better incorporate technologies into EFL classrooms.
\end{abstract} CALL

Index Terms - language learning technology, teaching, EFL,

\section{Introduction}

The emergence and development of CALL in the 1990s was pushed by new technology which was introduced into the language classroom and evaluated according to Second Language Acquisition (SLA) principles. SLA principles were known to create effective learning environments. These principles improved student language learning by providing opportunities for real social interaction, the performance of genuine tasks and the creative use of languages; in addition, teachers focused on the learning process and learning strategies, appropriate feedback and time to carry out tasks, and support for learner autonomy (Egbert and Hanson-Smith 1999).

Chapelle $(1995,1997)$ was an early voice leading this theory, while Egbert and Hanson-Smith (1999) laid out a text that gave teachers concrete ideas on how to apply SLA techniques in the classroom, such as using email pen-pals to encourage students to interact with others in the target language, and choosing software that allowed students to work at their own individual pace and make choices about the tools that they chose to use or ignore, thus boosting autonomy. The work of Egbert and Hanson-Smith (1999) continues to give EFL teachers a solid foundation on which to design their lessons. Up until this point in the area of CALL, it provides valuable ideas on how to connect technology use in the classroom with sound language learning pedagogy.

However, it is noticed that most EFL teachers approach the use of technology with a variety of strong assumptions. Importantly, if these assumptions are not identified and addressed, they will impact the way that the teachers interpret the importance of SLA principles when using language technologies. Therefore, there is a critical need to make sense of these initial assumptions when developing approaches to modern language learning technologies in EFL classroom for the teachers.

\section{Warschauer's Model and Teachers' Technology-teaching Assumptions}

A. Warschauer's Model

One way to accomplish this is to adopt Warschauer's (1998) framework, which explains the largely different perspectives with which researchers in language technology approach their work, and provides an essential bridge between varying sets of assumptions. Although Warschauer (1998) was describing researchers' perspectives, the framework is easily applied to help teachers identify their own approaches to language teaching technology and to thoughtfully explore and consider other approaches. It could hopefully lead to a well-informed and productive use of technology in the EFL classroom.

Warschauer (1998) suggests that researchers working in the field of language technology approach their work form very different positions. These differences have a great influence on the assumptions that they hold and the conclusions they draw. Warschauer identifies the three positions as: determinist, instrumental and critical.

1) Determinist Position: According to Warschauer (1998), a determinist position associates the mere presence of computer with successful language learning. In other words, technology has a "magic" effect on learning and simply including it will determine a more positive result for any activity.

2) Instrumental Position: Those who hold the instrumental perspective believe that technology is just a tool that is not capable of bringing about positive learning outcome in and of itself. Although technology can be instrumental in leading to effective language learning, it all depends on the abilities of the teacher to implement CALL in the classroom.

3) Critical Position: The critical position regarding language learning technology indicates that a learning environment is its own ecosystem and that any addition to the ecosystem brings about a slightly or radically different learning environment. These subtle or obvious changes are often sociocultural; there maybe shifts in power, identity, or communication patterns or changes in relationships between individuals and groups (Petrie and Avery, 2011).

\section{B. Application of Warschauer's Model to Teachers' Technology Assumptions \\ Warschauer (1998) dismisses the determinist approach,}


recognizes the value the instrumental approach and encourages researchers to adopt a critical view of technology (Petrie and Avery, 2011). A variation on this model helps teachers to identify their own and other's positions and to respond by making informed decisions regarding appropriate activities related. EFL teachers may be predisposed to believe that the mere presence of technology will bring about not only positive results in their classrooms, but also negative results. Therefore, 1) a teacher who takes up the determinist position may be a lover of technology, and he may be certain that it will solve any teaching problems; or he may be a hater of technology and certain that it will destroy all teaching. 2) A teacher may hold the instrumental position considering technology as a neutral tool and being certain that its success or failure is entirely dependent on the instructional choices that are made. 3) Another groups of teachers may hold critical position viewing technology as capable of influencing classrooms in deep, subtle and unpredictable ways and being certain that sociocultural elements should be considered when using and evaluating technology use.

\section{Activity Ideas for Developing EFL Teachers' Approaches to Teaching with Technology}

Based upon the identification of their own initial assumptions about the use of technology in the classroom, EFL teachers can be engaged in some professional development activities to help them enhance their approaches to teaching with technology.

\section{A. Activity Ideas for Technology-lover Type of Teachers}

For those teachers who identify themselves as technology-lovers, they believe technology can solve any problems in teaching. Therefore, the activities should include elements to encourage teachers to give up the assumption that technology will automatically bring about improved language learning outcomes in the classroom. The activities will also enhance a deeper understanding of the important role that teachers have in designing classes that incorporate technology. Some activity can provide an opportunity for teachers to become aware of both instructional choices and their results, while some other activity can help teachers develop their awareness of the individual characteristics of technologies and their suitability or unsuitability for use in teaching many skills and sub-skills across a language.

Teachers can carry out an activity of comparing lessons that incorporate technology, for example. To begin, everyone gets the same English language item and the same technology to which they have access. Then, teachers are supposed to independently create a short lesson to teach the language item using the technology. Teachers should make a detailed lesson plan to hand out to the other course participants. All the participants get the chance to experience the lessons the course members have made. They exchange lesson plans and discuss the differences in choices. They make an evaluative discussion of which instructional elements made some technology uses more effective. It is likely that the participants will discover a wide range of choices of different quality, good or bad, suitable or unsuitable.

\section{B. Activity Ideas for Technology-hater Type of Teachers}

For those teachers who identify themselves as technology-haters, some activities should be organized to increase the teacher's comfort level with using technology to impart effective language lessons. A "technology petting zoo" (Petrie and Avery, 2011) could be built in this respect. It requires different technologies to be accessible in a computer lab or other room and set up in separate stations. A combination of several types of technologies which are considered useful for language teaching includes: 1) Resources: a place for teachers and students to access content such as dictionaries and video collections; 2) Creation tools: a way for students to produce documents, presentations or other products with appropriate programs; 3) Widgets: a station where students can work with special applications; 4) Hardware: a tool teachers can pick up and handle that can be used in teaching, such as mini voice recorders and digital cameras. In addition, it is crucial to make clear directions for each technology station so that teachers know how to operate the technology and can thoughtfully consider how they would use it in their classrooms.

Another way is to explore emerging technologies. Teachers could make efforts to catch the information describing the technologies that have made their way into language teaching. Teachers can make a group discussion to reach a consensus about the technologies they would like to explore. Alternatively, individual teachers can choose the technology that most interests them and to which they have access, and then present the technology to group, emphasizing the technology's potential to enhance language learning chances.

\section{Activity Ideas for Teachers to Foster the Critical Position}

A teacher in the critical position believes that sociocultural elements should be considered when using and evaluating technology use. For those who identify with the instrumental position, it is significant to encourage teachers to consider the sociocultural contexts and impact of technology on language learning, and it proves useful for all teachers as they develop a critical perspective about CALL in the classroom.

For many teachers, the consideration of sociocultural contexts is a challenging task. Both Postman (1993) and McLuhan (1994) authored two enlightening texts to assist teachers to see classrooms as ecosystems that are influenced significantly by the introduction of technologies. It is essential for the teachers to reflect and make discussions on the ways that identity, relationships and communication are affected in unpredicted ways by technology. In this area, case studies can set the stage for rich discussions about the subtle and unexpected changes that occur when teachers incorporate technology into their classes. Case studies are especially powerful for increasing the awareness of power, literacy, relationship and spaces we create in classrooms (Petrie and Avery, 2011). Many resources can be tapped for the cases of technology incorporation that raise sociocultural questions. Good examples include Lam and Lawrence's (2002) case of a high school class and Lam's (2000) case of a high school 
student who develops language and literacy as his identity changes through online communication. The teachers can prepare the guiding questions about the cases and organize the case discussions. By this way teachers can be developed to foster the critical position in language learning technologies in EFL classrooms.

\section{Conclusion}

Against the backdrop of CALL's emergence and development, a few researchers and practitioners in this area noticed the situation of unclear understanding of different technology-teaching assumptions, and began to make sense of it, which helped to push the field forward (Chapelle 1995, 1997; Salaberry 1999). It proves essential to understand the range of assumptions that teachers bring with them regarding the integration of technology with language learning. Applying Warschauer's Model of researcher's approaches to language technology has offered us the guiding principles for responding to these assumptions with activities. The goals for all teachers are the same --- to develop comfort with language learning technologies, to approach them with innovation, to conform EFL teaching to SLA principles, and to consider the sociocultural impact of technology integration. Ultimately, that is to develop our teachers' approaches to language learning technologies in EFL Classroom.

\section{References}

[1] C. A. Chapelle, "A framework for the investigation of CALL as a context for SLA”, CAELL Journal, vol. 6, no. 3, pp.2-8, 1995.

[2] G. M. Petrie and L. Avery, "Identifying our approaches to language learning technologies: improving professional development", English Teaching Forum, vol. 49, no. 3, pp.11-15, 2011.

[3] J. Egbert and E. Hanson-Smith, CALL Environments: Research, Practice, and Critical Issues, Alexandria, VA: TESOL, 1999.

[4] M. Mcluhan, Understanding Media: the Extensions of Man, Cambridge, MA: MIT Press, 1994.

[5] M. Warschauer, "Researching technology in TESOL: determinist, instrumental, and critical approaches", TESOL Quarterly, vol. 32, no. 4, pp.757-761, 1998.

[6] N. Postman, Technopoly: the Surrender of Culture to Technology, New York: Vintage, 1993.

[7] R. Salaberry, "CALL in the year 2000: still developing the research agenda", Language Learning and Technology, vol. 3, no. 1, pp.104-107. 1999.

[8] Y. Lam and G. Lawrence, "Teacher-student role redefinition during a computer-based second language project: Are computers catalysts for empowering change?", Computer Assisted Language Learning, vol. 15, no. 3 , pp.295-315, 2002. 